\title{
Curcumin induces autophagy, inhibits proliferation and invasion by downregulating AKT/mTOR signaling pathway in human melanoma cells
}

\author{
GUANGMING ZHAO*, XIAODONG HAN*, SIWEN ZHENG, ZHEN LI, YANG SHA, \\ JING NI, ZHE SUN, SONG QIAO and ZHIQI SONG
}

Department of Dermatology, The First Affiliated Hospital of Dalian Medical University, Dalian, Liaoning 116011, P.R. China

Received July 31, 2015; Accepted September 26, 2015

DOI: $10.3892 /$ or.2015.4413

\begin{abstract}
Melanoma is the foremost malignant cutaneous cancer and it is extremely resistant to chemotherapy and radiotherapy. Curcumin is an active component of turmeric, the yellow spice derived from the rhizome of Curcuma longa, and is widely known for its anti-inflammatory and anti-cancerogenic properties. Several recent studies suggest that curcumin induces apoptosis by modulating multiple signaling pathways to exert its anticancer effect. In the present study, we investigated the effect of curcumin on the viability, invasion potential, cell cycle, autophagy and the AKT, mTOR, P70S6K proteins of AKT/mTOR signaling pathway in human melanoma A375 and C8161 cell lines in vitro and in an in vivo tumorigenesis model. Curcumin effectively inhibited the proliferation of melanoma cells in vitro and in vivo. It suppressed cell invasion, arrested the cancer cells at $\mathrm{G}_{2} / \mathrm{M}$ phase of the cell cycle, and induced autophagy. Furthermore, curcumin suppressed the activation of AKT, mTOR and P70S6K proteins. Curcumin, therefore, is a potent suppressor of cell viability and invasion, and simultaneously an inducer of autophagy in A375 and C8161 cells. Accordingly, curcumin could be a novel therapeutic candidate for the management of melanoma.
\end{abstract}

\section{Introduction}

Melanoma is a common form of aggressive cancer that originates from melanocytes. The prognosis for patients with early stage melanoma is $90 \%$ survival by surgical treatment. In contrast, the prognosis for advanced melanoma is restricted

Correspondence to: Professor Zhiqi Song, Department of Dermatology, The First Affiliated Hospital of Dalian Medical University, 222 Zhongshan Road, Dalian, Liaoning 116011, P.R. China E-mail: szqdalian@163.com

*Contributed equally

Key words: curcumin, melanoma, autophagy, proliferation, invasion, AKT/mTOR pathway largely due to chemoresistance of the cancer cells (1). In recent years, numerous chemical agents have been developed and used in the treatment of melanoma. Although these agents have immensely contributed to improve treatment outcomes for patients, they harbor some limitations, in that they are tumor resistance-prone and induce chemotherapy-related systemic toxicity (2). Consequently, the search for novel and non-toxic anti-melanoma agents remains urgent.

Curcumin is the primary bioactive component of turmeric, a dietary spice derived from the rhizome of Curcuma longa (3). It has long been used in Southeastern Asian medicine, and also in cooking to give food a natural yellow color. Cucumin possesses potent anti-inflammatory, antioxidant and above all, anticancer properties (4). Curcumin induces antiproliferative and apoptotic effects on several human melanoma cell lines (4-9). In addition, preclinical animal experiments and phase I clinical trials have certified curcumin to be of minimal toxicity, even at relatively high doses (12 g/day) (10). Although most chemotherapeutic drugs exert their cytotoxic effect by promoting apoptosis, recent studies indicate that autophagy could hold a promise in cancer therapy (11-14). However, there is paucity of information on the effect of curcumin on autophagy in melanoma. In the present study, we investigated the effects of curcumin on human melanoma A375 and C8161 cells through in vitro assessment of cell proliferation, cell cycle, cell invasion, autophagy and the activation of AKT, mTOR and P70S6K proteins. A murine explanted melanoma model was further used to evaluate the anticancer property of curcumin in vivo. We present evidence that curcumin induces autophagy, and inhibits proliferation and invasion of human melanoma cells by blocking the AKT/mTOR signaling pathway.

\section{Materials and methods}

Chemicals and reagents. Curcumin (no. A0086, CAS: 458-37-7, purity $>98 \%$ ) was purchased from Must Biotechnology Inc. (Chengdu, China). Dulbecco's modified Eagle's medium (DMEM) was purchased from Gibco-BRL (Grand Island, NY, USA). Dimethylsulfoxide (DMSO), 3-(4,5-dimethylthiazol2-yl)-2,5-diphenyl-tetrazolium bromide (MTT), Triton X-100, rapamycin and anti- $\beta$-actin antibody were purchased from Sigma Chemical (St. Louis, MO, USA). Matrigel was purchased 
from BD Company (Franklin Lakes, NJ, USA). Propidium iodide (PI) and RNase were purchased from Takara Biotechnology Inc. (Otsu, Shiga, Japan). Lipofectamine 2000 was purchased from Life Technologies (Carlsbad, CA, USA). The antibodies for LC3-I and LC3-II were purchased from Sigma-Aldrich (Shanghai, China). The antibodies for AKT, phosphorylatedAKT (Ser473), mTOR, phosphorylated-mTOR (Ser2448), P70S6K, phosphorylated-P70S6K (Thr389) were all purchased from Cell Signaling Technology (Beverly, MA, USA).

Cell culture and treatment. Human malignant melanoma A375 and C8161 cell lines were obtained from Union Cell Resource Center (Beijing, China) and were cultured and maintained in DMEM supplemented with $1 \%$ penicillin-streptomycin and $10 \%$ fetal bovine serum (FBS) at $37^{\circ} \mathrm{C}$ and $5 \% \mathrm{CO}_{2}$ in a humid incubator. Curcumin (dissolved in DMSO) was used to treat A375 and C8161 cells. Control cells were treated with equivalent volume of DMSO.

Cell viability. The effect of curcumin on the viability of the cells was determined by MTT assay. Briefly A375 and C8161 cells were plated at $1 \times 10^{4}$ cells/well in $200 \mu \mathrm{l}$ culture medium into 96 -well plates. Different concentrations of curcumin $(15-75 \mu \mathrm{M})$ were added to different wells and incubated at $37^{\circ} \mathrm{C}$ for 24, 48, 72 and $96 \mathrm{~h}$. Following incubation for the specified time, $20 \mu \mathrm{l}$ MTT solution [5 $\mathrm{mg} / \mathrm{ml}$ in phosphate-buffered saline (PBS)] was added to each well and incubated for additional $4 \mathrm{~h}$. The culture medium in each well was replaced with $200 \mu \mathrm{l}$ of DMSO to dissolve the formazan crystals that were formed from the MTT assay. Absorbance of the solution was read at a wavelength of $490 \mathrm{~nm}$ on a microplate reader (T17108U; Perkin-Elmer, USA).

Cell invasion assay. To measure the three-dimensional movement of the cells, cell invasion assay was performed using Transwell chambers with $8-\mu \mathrm{m}$ pore polycarbonate filter inserts (Corning, New York, NY, USA). The upper side of each insert was coated with $10 \mu \mathrm{l}$ of Matrigel $(3 \mathrm{mg} / \mathrm{ml}$; Becton-Dickinson, Mountain View, CA, USA). A375 and C8161 cells $\left(1 \times 10^{6} / \mathrm{ml}\right)$ were separately cultured on Matrigel-coated Transwell inserts in DMEM supplemented with curcumin (25 and $15 \mu \mathrm{M}$, respectively), or DMSO. The lower chamber contained DMEM culture medium appended with $10 \%$ FBS as a chemoattractant. After $72 \mathrm{~h}$ of incubation, the invaded cells on the lower surface of the membranes were fixed with chilled $3.7 \%$ methanol for $15 \mathrm{~min}$ and stained with $0.5 \%$ crystal violet for $15 \mathrm{~min}$. Cells were visualized using inverted light microscope, and invasiveness was determined by counting the number of cells appearing on the undersurface of the polycarbonate membranes in five random, non-overlapping fields at a magnification of $x 200$. The average number of invaded cells in the five fields was taken to represent the mean cell invasion. The experiments were performed in triplicate.

DNA cell cycle analysis. A375 and C8161 cells were treated with curcumin (25 and $15 \mu \mathrm{M}$, respectively) at $37^{\circ} \mathrm{C}$ and $5 \%$ $\mathrm{CO}_{2}$ atmosphere for $24 \mathrm{~h}$. Cells were harvested and fixed in chilled $75 \%$ alcohol for $4 \mathrm{~h}$. Prior to analysis, a staining solution containing $480 \mu \mathrm{l}$ PBS, $5 \mu \mathrm{l}$ PI $(5 \mathrm{mg} / \mathrm{ml}), 5 \mu \mathrm{l}$ RNase $(10 \mathrm{mg} / \mathrm{ml})$ and $10 \mu \mathrm{l}$ Triton X-100 (10\%) was added to resuspend the cell pellet and incubated in the dark for $30 \mathrm{~min}$ at room temperature. Cells were analyzed by flow cytometer (Accuri C6; BD, USA) for cell cycle phase distribution.

Transfection and fluorescence microscopy. Cells were transfected with a plasmid expressing GFP-LC3 using Lipofectamine 2000 according to the manufacturer's instructions. After $16 \mathrm{~h}$ post-transfection with GFP-LC3, A375 and C8161 cells were incubated with curcumin $(25$ and $15 \mu \mathrm{M}$, respectively) or rapamycin ( $100 \mathrm{nM}$, used as a positive control) or DMSO at $37^{\circ} \mathrm{C}$ for $24 \mathrm{~h}$. Dot formation by GFP-LC3 was detected under a fluorescence microscope (DP73; Olympus, Japan) following drug treatment. Transfected cells were considered to have accumulated autophagosomes when five or more puncta were observed. A total of 100 transfected cells were examined/well, and the percentage of cells showing autophagy were counted in triplicate. The experiment was independently repeated three times.

Transmission electron microscopy. Cells were harvested by scraping from the plates. They were then washed twice with PBS and fixed with $2.5 \%$ glutaraldehyde and $1 \%$ (v/v) osmic acid, followed by an increasing gradient dehydration step using ethanol and acetone. Cells were then embedded in epoxy resin and ultrathin sections were cut, and stained with $0.2 \%$ lead citrate and $1 \%$ uranyl acetate. Images were captured with a transmission electron microscope (JEM 1011CX; JEOL, Japan).

Western blotting. After treatment of A375 and C8161 cells with curcumin ( 25 and $15 \mu \mathrm{M}$, respectively) for $24 \mathrm{~h}$, the cells were harvested and incubated in lysis buffer on ice for $30 \mathrm{~min}$. Then the lysate was clarified by centrifugation at $12,000 \mathrm{x} \mathrm{g}$ for $10 \mathrm{~min}$ at $4^{\circ} \mathrm{C}$ to obtain the supernatant (total cell lysate). The total protein concentration was determined using the Coomassie brilliant blue (CBB) method. For western blotting, $25 \mu \mathrm{g}$ of total protein was separated by sodium dodecyl sulfate-polyacrylamide gel electrophoresis (SDS-PAGE) and transferred onto nitrocellulose membranes. After blocking of non-specific binding sites with $5 \%$ non-fat dry milk for $2 \mathrm{~h}$ at room temperature, membranes were incubated with respective primary antibodies at appropriate concentrations overnight at $4^{\circ} \mathrm{C}$. After washing the membranes to remove unbound primary antibodies, they were incubated with either horseradish peroxidase-conjugated anti-rabbit or anti-mouse secondary antibody $(1: 5,000)$ for $1 \mathrm{~h}$ at room temperature. Finally the membranes were washed with PBS and chemiluminescence developed using ECL kit (APG BIO, Shanghai, China) for $1 \mathrm{~min}$. Protein bands were visualized by image scanning and the optical density for each band was measured using Image Lab software (version 4.0; Bio-Rad, USA) after data were normalized to $\beta$-actin as an internal control.

In vivo antitumor activity assay. All the animal experiments were carried out in strict accordance with the institutional guidelines for the ethical treatment of animals. The protocol was approved by the Ethics Committee of the Laboratory Animal of Dalian Medical University (permit no. L2015012). Six-week-old female BALB/c nude mice (Institute of Animal Center, Chinese Academy of Sciences, Shanghai, China) were housed in laminar flow rooms with stable temperature and 
A
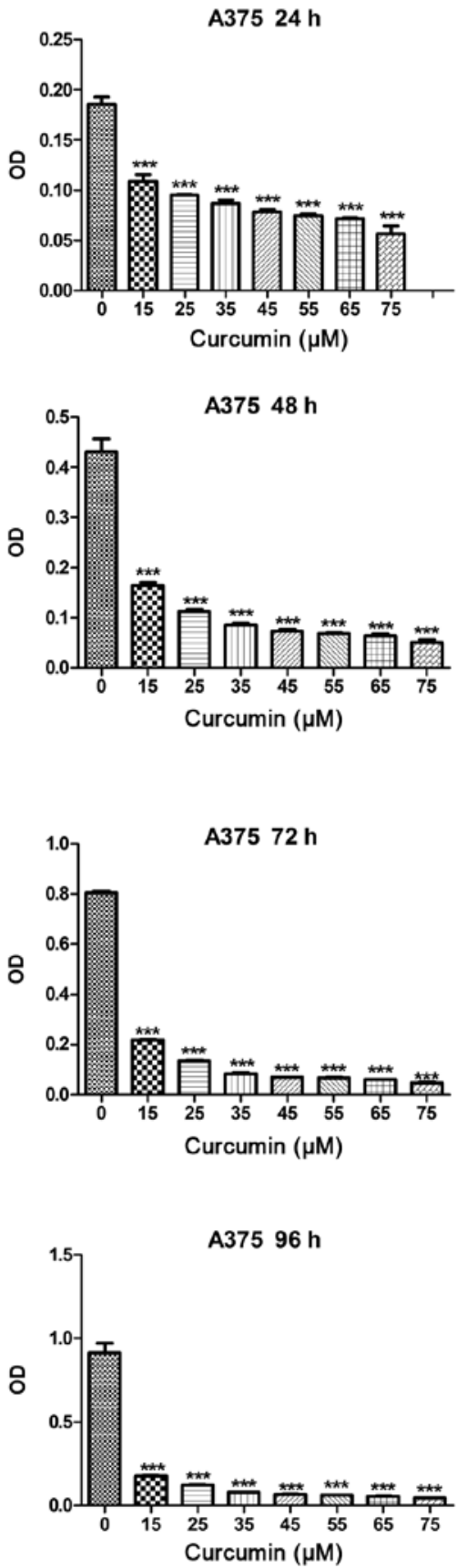
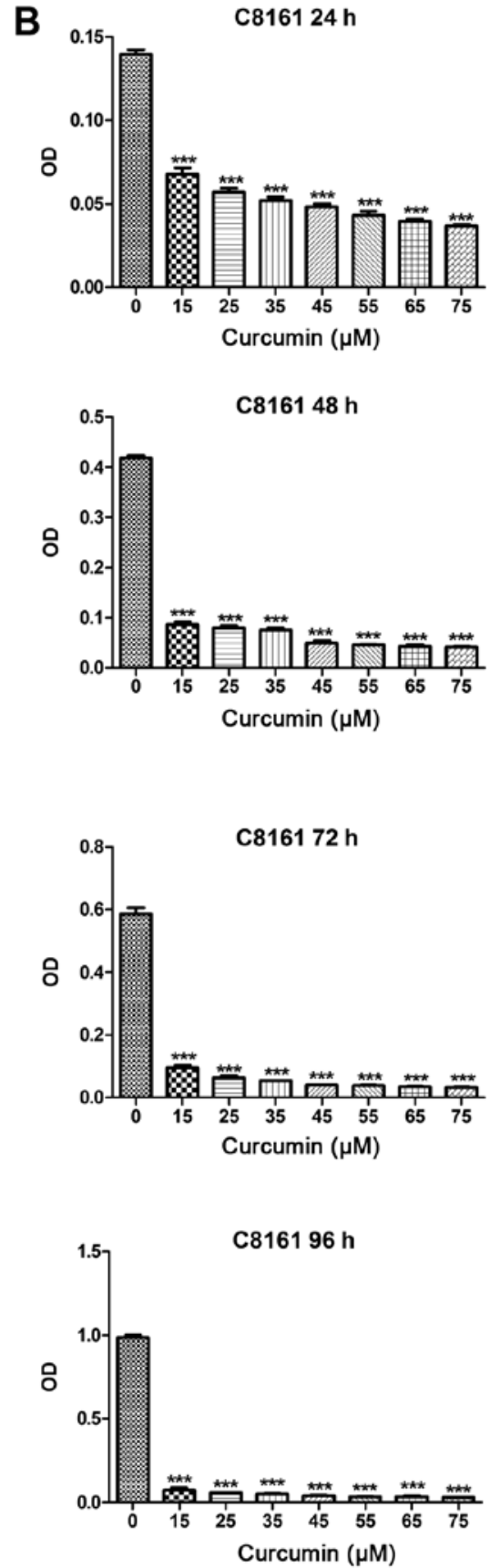

Figure 1. Antiproliferative effect of curcumin on A375 and C8161 cells. Cells were seeded into 96-well plates and incubated with the indicated concentration of curcumin $(15-75 \mu \mathrm{M})$ for 24, 48, 72 and $96 \mathrm{~h}$. Cell proliferation was analyzed by MTT assay. (A) Absorbance of A375 cells. (B) Absorbance of C8161 cells. Data are mean $\pm \mathrm{SD}$ of three separate experiments in which each treatment was carried out in triplicate. ${ }^{* * *} \mathrm{P}<0.001 \mathrm{vs}$. control.

humidity conditions. Human melanoma A375 cells (1x107/ml) resuspended in PBS were injected subcutaneously into the right flank of each mouse. The mice were randomly assigned to two groups ( $\mathrm{n}=5 /$ group). Therapy was initiated on the eighth day post-inoculation with A375 melanoma cells. Mice from the control and therapeutic groups received intraperitoneal injections of DMSO or curcumin $(25 \mathrm{mg} / \mathrm{kg})$, respectively, every day for 3 weeks. Tumor size was monitored before every injection using calipers at 3 days interval, and tumor volume was calculated using the formula: Volume $\left(\mathrm{mm}^{3}\right)=($ maximal length) $x$ (perpendicular width $)^{2} / 2$. All the mice were sacrificed 21 days after treatment. In addition, the tumors were resected for analyses.
Statistical analysis. All the experiments were carried out in triplicate and values are expressed as mean \pm standard deviation (SD). SPSS v17.0 software (SPSS, Inc., Chicago, IL, USA) was used for statistical analysis. The Student's t-test was used for the assessment of differences between groups. A probability of $\leq 0.05$ was deemed statistically significant. In the figures: ${ }^{*} \mathrm{P}<0.05,{ }^{* *} \mathrm{P}<0.01$ and ${ }^{* * *} \mathrm{P}<0.001$, relative to controls.

\section{Results}

Curcumin exhibits antiproliferative effect on A375 and C8161 cells. We first studied the inhibitory effect of curcumin on the growth of A375 and C8161 cells by employing MTT assay. 


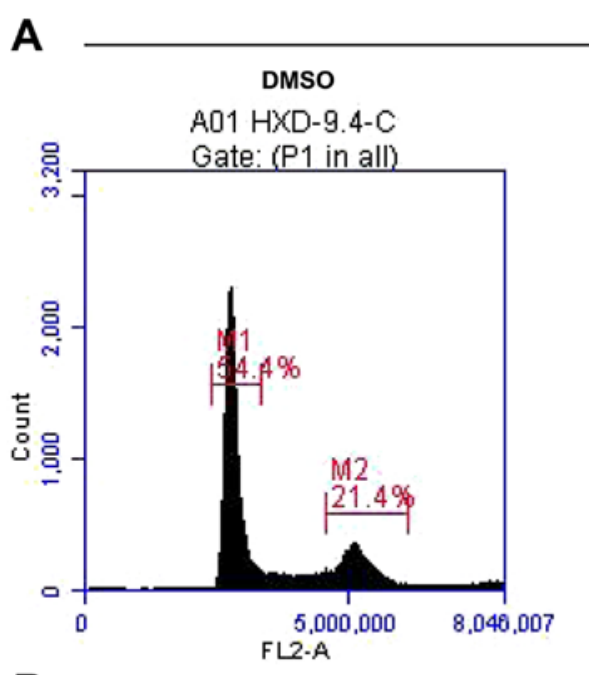

A375

B
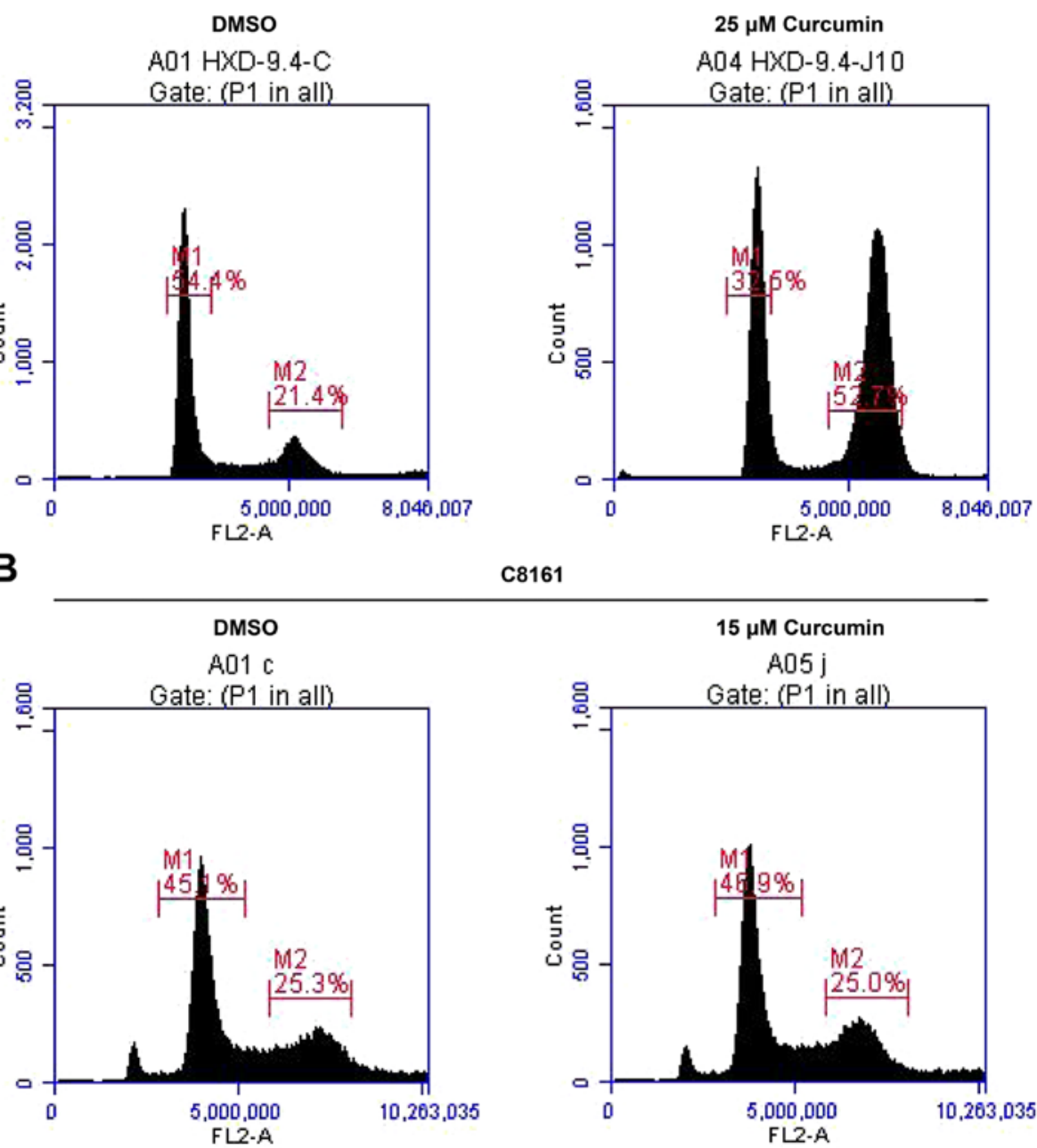

C8161

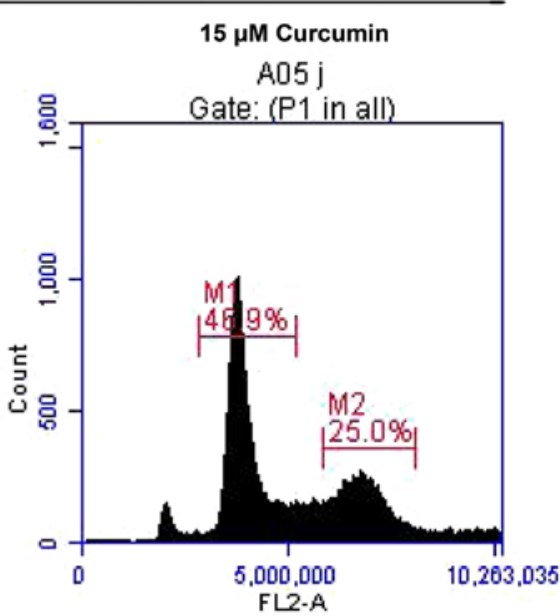

Figure 2. Effect of curcumin treatment on cell cycle distribution in A375 and C8161 cells. A375 and C8161 cells were treated with curcumin ( 25 and $15 \mu \mathrm{M}$, respectively) for $24 \mathrm{~h}$. Cellular DNA was stained with PI and analyzed by flow cytometry. The percentage of cells in the $\mathrm{G}_{0} / \mathrm{G}_{1}$ and $\mathrm{G}_{2} / \mathrm{M}$ phases was calculated using matched software of Accuri C6. (A and B) DNA content frequency histograms of untreated (DMSO) or $25 \mu \mathrm{M}$ curcumin-treated (A375) or 15 $\mu \mathrm{M}$ curcumin-treated (C8161) cells. Histograms are representative of three independent experiments.

Table I. Effect of curcumin on cell cycle progression in A375 and C8161 cells.

\begin{tabular}{lccccc}
\hline & \multicolumn{2}{c}{$\mathrm{A} 375$} & & \multicolumn{2}{c}{$\mathrm{C} 8161$} \\
\cline { 2 - 3 } Curcumin concentrations & $\mathrm{G}_{0} / \mathrm{G}_{1}(\%)$ & $\mathrm{G}_{2} / \mathrm{M}(\%)$ & & $\mathrm{G}_{0} / \mathrm{G}_{1}(\%)$ & $\mathrm{G}_{2} / \mathrm{M}(\%)$ \\
\hline $0(\mu \mathrm{M})$ & $51.80 \pm 3.29$ & $21.30 \pm 0.75$ & & $44.57 \pm 1.00$ & $25.23 \pm 2.31$ \\
$15(\mu \mathrm{M})$ & - & - & & $43.53 \pm 2.33$ & $33.80 \pm 1.25^{\mathrm{a}}$ \\
$25(\mu \mathrm{M})$ & $33.40 \pm 6.84$ & $48.07 \pm 7.09^{\mathrm{a}}$ & & - & - \\
\hline
\end{tabular}

Treatment of A375 and C8161 cells with curcumin ( 25 and $15 \mu \mathrm{M}$, respectively) resulted in a remarkable accumulation of cells in $\mathrm{G}_{2} / \mathrm{M}_{\text {phase }}$ and a reduction in $\mathrm{G}_{0} / \mathrm{G}_{1}$ cell population during the cell cycle. ${ }^{\mathrm{a}} \mathrm{P}<0.01$, compared to control group (treated with DMSO, i.e. $0 \mu \mathrm{M}$ curcumin).

Cells were treated with different doses of curcumin $(15-75 \mu \mathrm{M})$ for different periods of time (24-96 h). MTT assay showed that curcumin was effective in inhibiting the proliferation of A375 and C8161 cells in a dose-dependent, as well as time-dependent manner (ranging from 15-35 and 15-25 $\mu \mathrm{M}$, respectively, within $48 \mathrm{~h}$ (Fig. $1 \mathrm{~A}$ and B). The $\mathrm{IC}_{50}$ value at $24 \mathrm{~h}$ was estimated to be 25 and $15 \mu \mathrm{M}$, respectively (Fig. $1 \mathrm{~A}$ and B).
Curcumin arrests $A 375$ and $C 8161$ cells at $G_{2} / M$ phase in the cell cycle. Since curcumin treatment inhibited A375 and C8161 cell growth, we next examined whether growth inhibitory effect of curcumin was mediated through cell cycle arrest. For this purpose, the effect of curcumin on cell cycle progression in A375 and C8161 cells was determined by flow cytometry. Treatment of A375 and C8161 cells with curcumin 
(25 and $15 \mu \mathrm{M}$, respectively) resulted in a remarkable accumulation of cells in $G_{2} / M$ phase and a reduction in $G_{0} / G_{1}$ cell population during the cell cycle (Fig. 2, Table I). This profound decrease in $G_{0} / G_{1}$ phase cell population suggests a $G_{2} / M$ phase cell cycle arrest of melanoma cells upon exposure to curcumin and that blockage of cell cycle progression may be one of the mechanisms by which curcumin inhibits A375 and C8161 cells growth.

Curcumin inhibits A375 and C8161 cell invasion potential. The Matrigel model of the basement membrane was employed as a cell invasion barrier to quantify the invasive potential of A375 and C8161 cells. The density of invaded cells on the membrane and the number of invaded cells/microscopic field are shown in Fig. 3. Treatment with curcumin (25 and $15 \mu \mathrm{M}$, respectively) for $72 \mathrm{~h}$ significantly reduced the invasive potential of A375 and C8161 melanoma cells as compared to their untreated control cells $(\mathrm{P}<0.001)$. When $\mathrm{A} 375$ cells were treated with $\geq 35 \mu \mathrm{M}$ curcumin and C8161 cells treated with $\geq 25 \mu \mathrm{M}$ curcumin for $72 \mathrm{~h}$, no invading cells could be seen (data not shown), suggesting that curcumin may antagonize the invasive potential of melanoma cells, as evidenced on A375 and C8161 cells.

Curcumin promotes autophagy in A375 and C8161 cells. LC3 is now believed to be a reliable marker for autophagy. A375 and C8161 cells were treated with DMSO, rapamycin (100 $\mathrm{nM}$ ) or curcumin (25 and $15 \mu \mathrm{M}$, respectively). As shown in Fig. 4A, autophagic vacuoles and autolysosomes accumulated in rapamycin- and curcumin-treated groups, while none was observed in DMSO-treated group (Fig. 4A). In the absence of any treatment, diffuse LC3 fluorescence was observed. Following treatment with curcumin, punctate fluorescence, which was similar to that produced by the canonical autophagy inducer rapamycin, was observed (Fig. 4B). Curcumin caused an obvious increase in the number of cells with GFP-LC3 punctate dots in both A375 and C8161 cells (Fig. 4C, P<0.001). During autophagy, LC3-II is recruited to the autophagosome. We found that LC3-II level was significantly increased with 25 and $15 \mu \mathrm{M}$ curcumin treatment of A375 and C8161 cells as compared to DMSO treatment (Fig. 4D, $\mathrm{P}<0.001, \mathrm{P}<0.05$ ). These results revealed that curcumin could potently induce autophagy in both A375 and C8161 cells.

Curcumininhibits the activation of PI3K/AKT/mTOR signaling pathway. Since growth factor signaling can directly regulate autophagy through mTOR pathway, western blotting against phospho-AKT, AKT, phospho-mTOR, phospho-P70S6K and P70S6K were performed. Under the indicated concentration of curcumin treatment of A375 and C8161 cells, the expression of PI3K downstream activated proteins, p-AKT, p-mTOR and p-P70S6K, significantly decreased as compared to DMSO treated cells (Fig. 5).

Inhibition of melanoma growth in vivo by curcumin treatment. BALB/c nude mice were inoculated with A375 melanoma cells to establish an explanted in vivo melanoma model. After 21 days of treatments with either curcumin or DMSO, tumors in the curcumin-treated group were generally smaller than tumors in corresponding DMSO-treated animals (Fig. 6A).
A A375
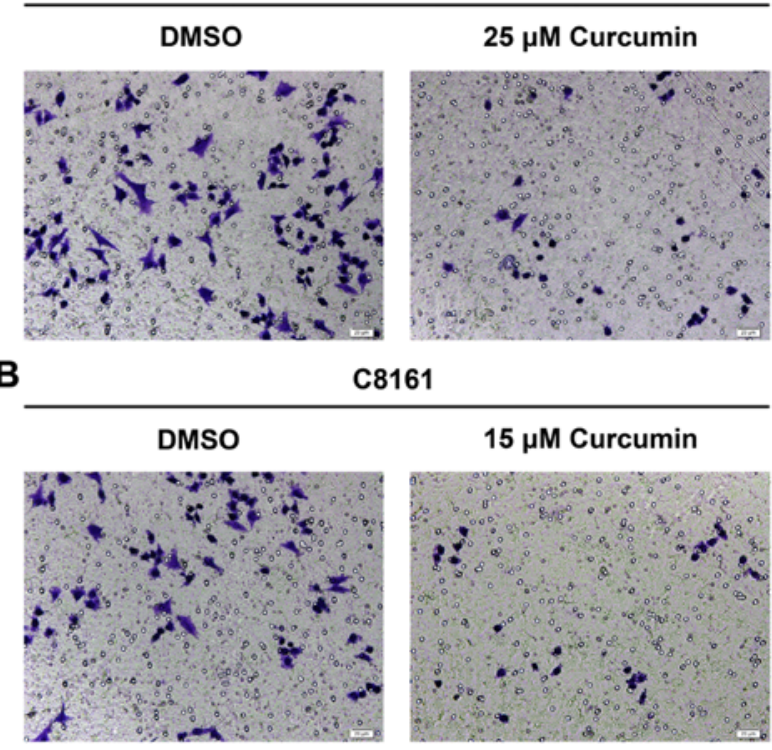

$15 \mu \mathrm{M}$ Curcumin

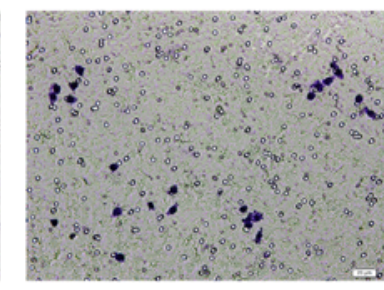

C

A375 72 h

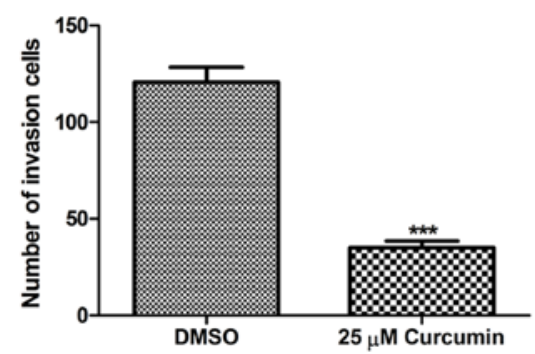

D

C8161 $72 \mathrm{~h}$

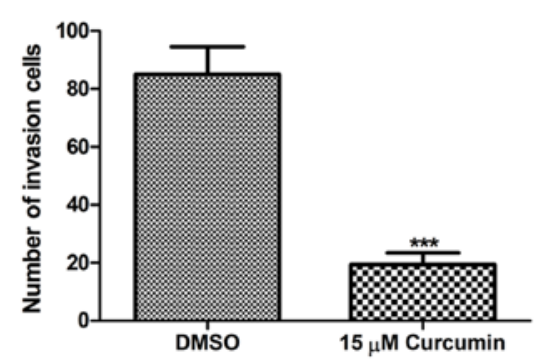

Figure 3. Effect of curcumin treatment on invasive behavior of A375 and C8161 cells. The invasive capacity of A375 and C8161 cells was determined by employing Transwell chamber assay as described under Materials and methods. (A and B) Representative photomicrographs of the inhibition of A375 and C8161 cell invasion following treatment with 25 and $15 \mu \mathrm{M}$ curcumin, respectively (crystal violet staining, magnification, x200, representative image from three independent experiments). (C and D) Histogram of the number of invaded cells following treatment with varying concentrations of curcumin $(0,25$ and $15 \mu \mathrm{M}$, respectively). The invaded cells were counted in five randomly selected microscopic fields on the membrane and the results were summarized and expressed as the mean number of invaded cells $\pm \mathrm{SD} /$ microscopic field. Treatment group vs. control group, ${ }^{* * *} \mathrm{P}<0.001$.

The average tumor weight in curcumin-treated mice was also markedly less as compared to tumors from control mice (Fig. 6B). However, the difference between the average tumor volumes of the two groups was not statistically significant (data not shown). Curcumin, thus may suppress melanoma growth in vivo. 
A

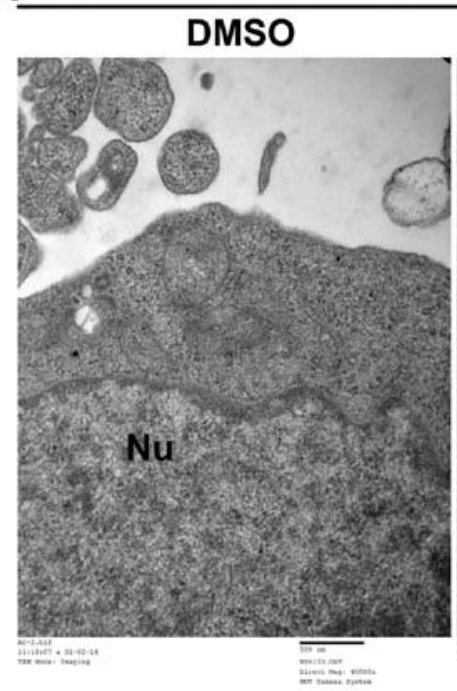

100 nM Rapamycin

$25 \mu \mathrm{M}$ Curcumin
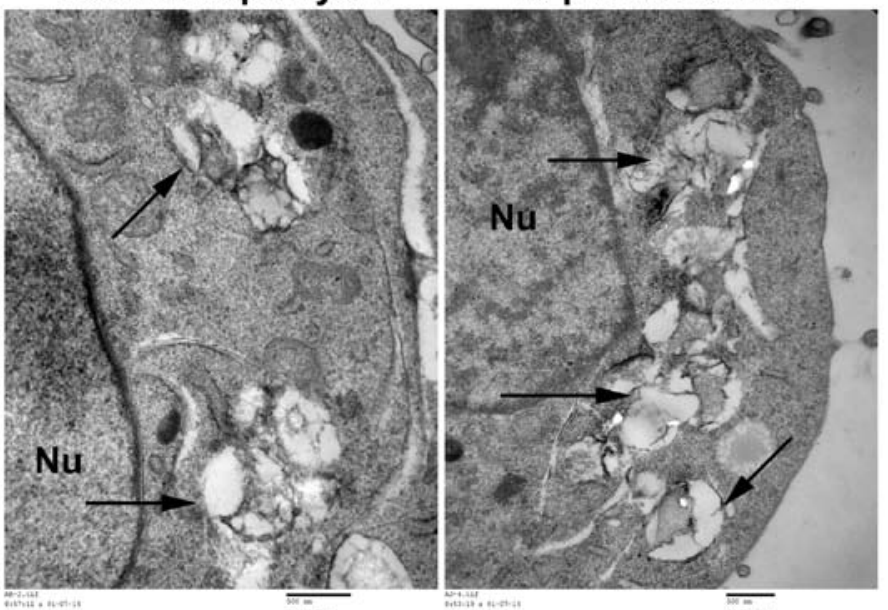

C8161
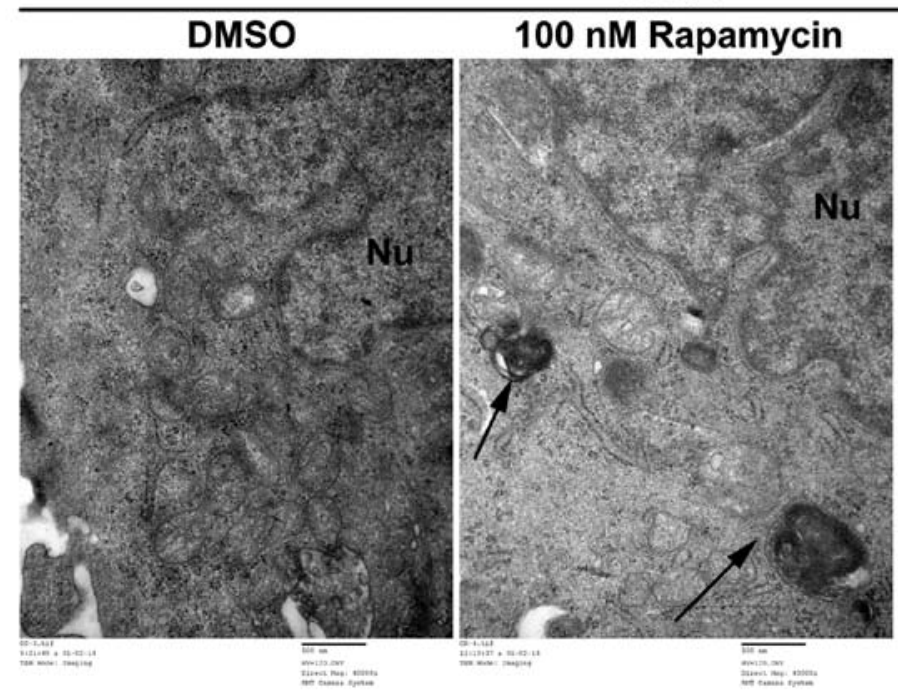

$15 \mu \mathrm{M}$ Curcumin

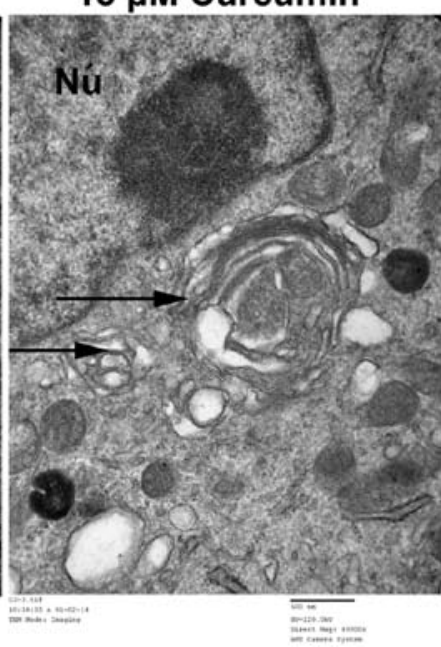

B A375

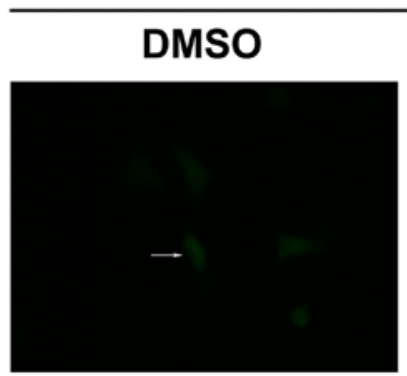
100 nM Rapamycin

$25 \mu \mathrm{M}$ Curcumin
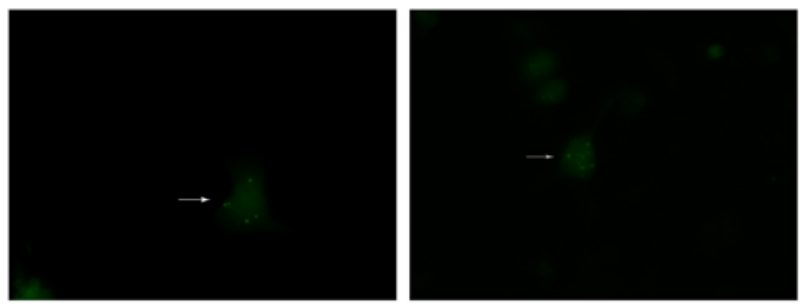

C8161

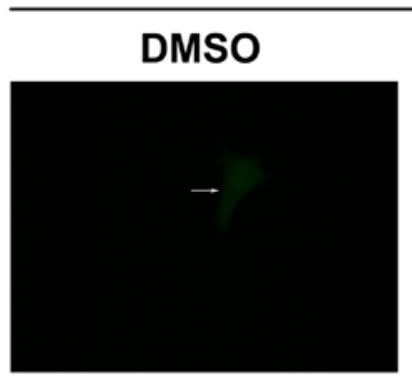
100 nM Rapamycin

$15 \mu \mathrm{M}$ Curcumin
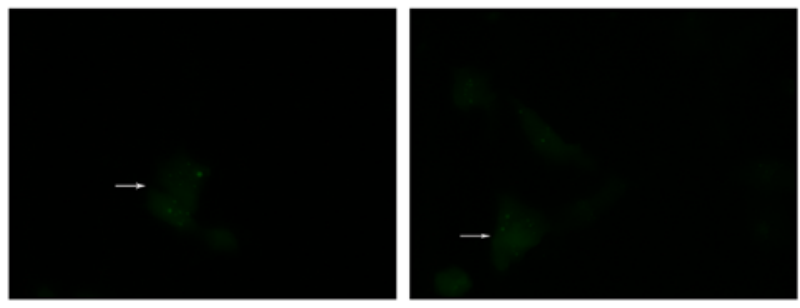

Figure 4. Induction of autophagy by curcumin in A375 and C8161 melanoma cells. (A) Transmission electron microscopy images of the ultrastructure of A375 and C8161 melanoma cells treated with either DMSO (negative control), rapamycin (positive control) or curcumin for $24 \mathrm{~h}$. Arrowheads indicate autophagosomes; Nu, nucleus. (B) LC3 fluorescence puncta indicating autophagosomes in the cells. 
C

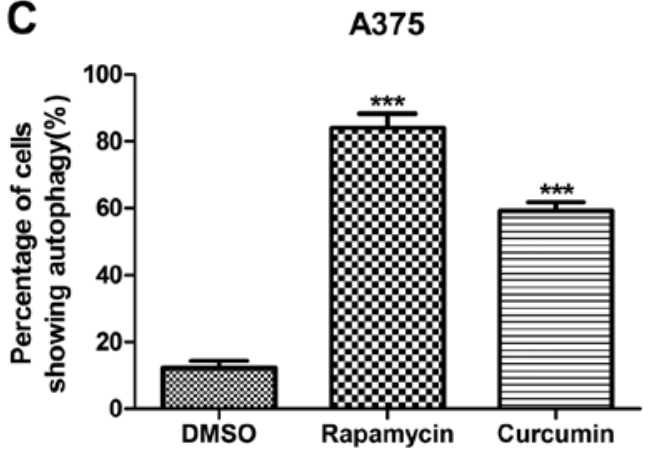

D

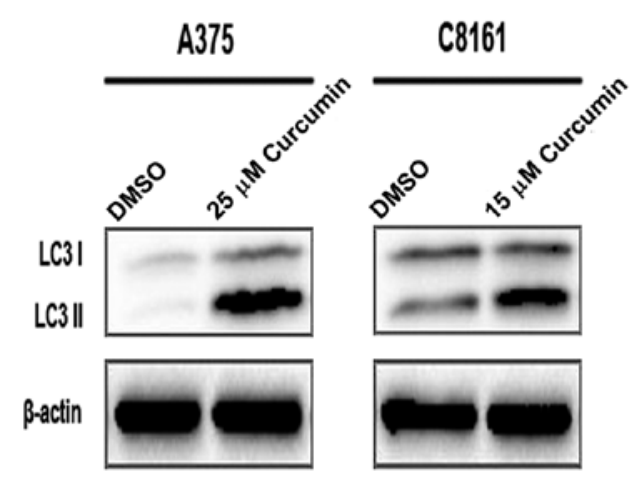

C8161
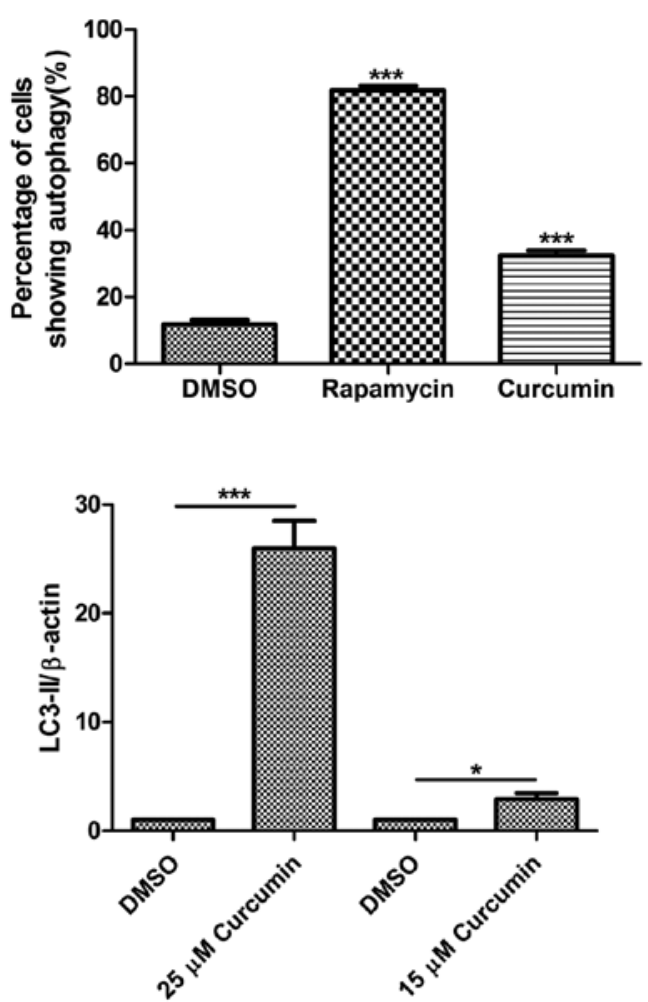

Figure 4. Continued. (C) Histograms of the percentage of cells showing LC3 puncta (mean \pm SD) $\left.{ }^{* * * *} \mathrm{P}<0.001\right)$. (D) A375 and C8161 melanoma cells were treated with the indicated concentration of curcumin for $24 \mathrm{~h}$ and analyzed by immunoblotting with antibodies against LC3 or $\beta$-actin. Actin was used as loading control. All blots shown are representative of at least three independent experiments. ${ }^{*} \mathrm{P}<0.05,{ }^{* * *} \mathrm{P}<0.001$.

\section{Discussion}

Melanoma is regarded as one of the most malignant cancers. In 2014, 76,100 new cases of melanoma was diagnosed in the US alone, and an estimated 9,710 deaths occurred from the disease (15). Currently, the major challenges to conventional antitumor agents include chemoresistance, and severe-systemic adverse effects (16-18). Therefore, growing interests have focused on the search for novel alternative medicines both safe and effective against melanoma. Phytochemical compounds have shown fairly promising potential as anti-carcinogen (19). In the present study, we explored the chemotherapeutic capacity of curcumin against human melanoma.

We used human melanoma A375 and C8161 cell lines with different BRAF mutation status. A375 cells harbor the $B R A F^{V 600 E}$ mutation, unlike C8161 cells which harbor BRAF wild-type gene. Curcumin, as evidenced in the present study, observably inhibited the growth of both A375 and C8161 cells (Fig. 1). It could also significantly decrease the tumor weight in a murine melanoma model (Fig. 6). These data, in vitro and in vivo, strongly suggest curcumin have chemotherapeutic potential against melanoma.

$\mathrm{G}_{2} / \mathrm{M}$ checkpoint is one of the well-known cell cycle checkpoints. Defective checkpoint function fosters genetic modifications that contribute to tumorigenesis. The regulation of checkpoint signaling offers important clinical influences because the abrogation of checkpoint function can alter the sensitivity of tumor cells to chemotherapeutics (20). Moreover, cell cycle arrest is considered to be an effective strategy for eliminating cancer cells (21). We found that curcumin inhibited the growth of A375 and C8161 cells by inducing cell arrest at $\mathrm{G}_{2} / \mathrm{M}$ phase of the cell cycle (Fig. 2). Our data support an earlier assertion by Zheng et al that curcumin may arrest cells at the $\mathrm{G}_{2} / \mathrm{M}$ transition in human melanoma cells (6).

It has been reported that the antiproliferative property of D6, a curcumin analogue, in melanoma could be partially due to the downregulation of the PI3K/AKT pathway (22). Proverbially $\mathrm{PI} 3 \mathrm{~K} / \mathrm{AKT} / \mathrm{mTOR} / \mathrm{P} 70 \mathrm{~S} 6 \mathrm{~K}$ pathway is a critical intracellular signaling pathway with respect to cell survival and death (23). The present study revealed that curcumin inhibited the activation of AKT, mTOR and P70S6K proteins (Fig. 5). AKT is active during mitosis and suppression of PI3K/AKT pathway facilitates cell cycle to arrest at $\mathrm{G}_{2} / \mathrm{M}$ transition through the regulation of CDK1 expression rather than cyclin B1 expression (24).

The pivotal signaling pathway that modulates invasion of tumor cells is the PI3K/AKT pathway (25). This pathway promotes resistance to chemotherapy-induced apoptosis in many types of cancer including melanoma (26). Several studies have reported that P70S6K has the potential to regulate cell motility (27). The effects of mTOR and P70S6K on migration may be correlated to synthesis of proteins required for cytoskeleton reorganization (28). Our results suggested that curcumin exhibited anti-invasion effect on A375 and C8161 cells (Fig. 3) and this could be via the downregulation of phospho-AKT, phospho-mTOR and phospho-P70S6K (Fig. 5).

Apoptosis has been generally recognized to be associated with oncogenic transformation and tumor development. However, an increasingly growing body of evidence indi- 
A

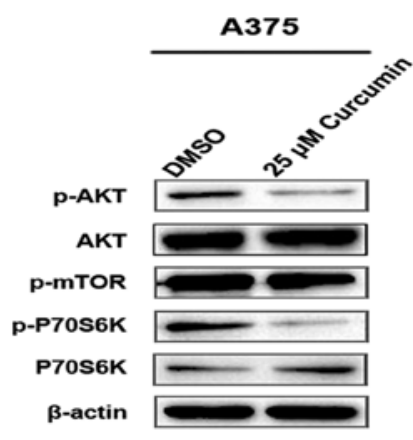

C8161

B

A375
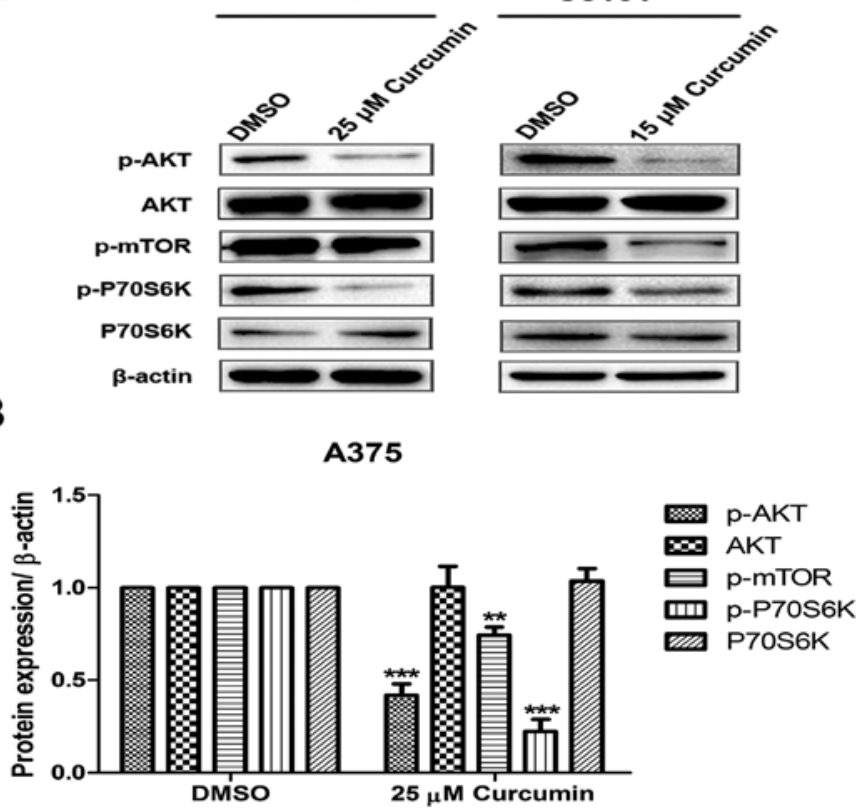

C8161

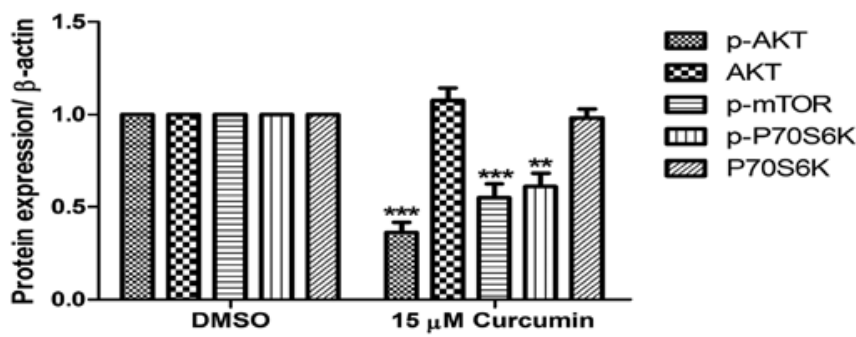

Figure 5. Inhibition of AKT/mTOR/P70S6K signaling pathway following curcumin treatment of A375 and C8161 cells. (A) A375 and C8161 cells were incubated with DMSO, 25 or $15 \mu \mathrm{M}$ curcumin for $24 \mathrm{~h}$. p-AKT, AKT, p-mTOR, P70S6K and p-P70S6K were analyzed by western blotting. (B) Relative amounts of the investigated proteins expressed in A375 and C8161 cells. Data are mean \pm SD of three experiments. ${ }^{* *} \mathrm{P}<0.01,{ }^{* * * *} \mathrm{P}<0.001$ vs. untreated control
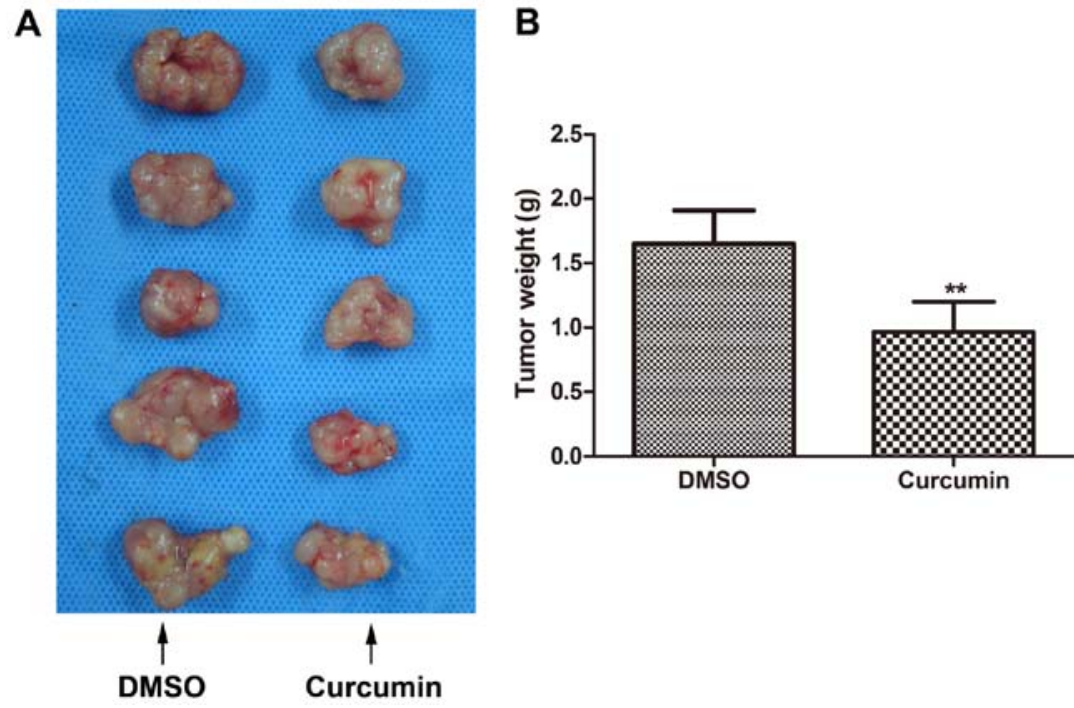

Figure 6. Curcumin treatment suppressed melanoma growth in vivo. (A) Images of tumors harvested 21 days post curcumin (right) or DMSO (left) treatment of BALB/c nude mice $(n=5)$ inoculated with A375 melanoma cells. (B) Average tumor weight from mice inoculated with A375 cells and treated with either DMSO or curcumin. ${ }^{* *} \mathrm{P}<0.01$

cates that autophagy may be of equivalent importance in tumorigenesis and as such a momentous target for cancer therapy (29). Recent studies suggest autophagy may play a role in resistance to chemotherapy (30-32). Autophagy is hence 
being explored as a therapeutic option for advanced cancers, such as in melanoma treatment (33). The present study revealed that curcumin significantly elevated the expression of LC3 which is a prominent marker of autophagy (Fig. 4). Chatterjee and Pandey (4) have also reported that curcumin treatment could induce autophagy in A375 cells. We demonstrated here that curcumin may not only induce autophagy in A375 cells, but also in BRAF mutation negative melanoma cells such as C8161. This is essential in that curcumin may be effective against melanoma subtypes which are resistant to BRAF inhibitors. However, further studies are needed for validation of this phenomenon. AKT negatively regulates autophagy in response to mitogens via activation of target of rapamycin (mTOR), which suppresses multiple autophagypromoting proteins via phosphorylation (34). In the present study, we found for the first time that treatment of curcumininduced autophagy via decreasing the phosphorylation of AKT, mTOR and P70S6K. Chatterjee and Pandey (4) have shown that curcumin in combination with tamoxifen, both at low doses, induce a synergistic increase in cell death of chemoresistant human melanomas as compared to the use of either drug alone. This observation was associated with increased induction of autophagy. Given this evidence, nontoxic curcumin is worthy of future clinical trials against chemoresistant human malignant melanoma.

In conclusion, curcumin is a potent suppressor of cell viability and invasion, and simultaneously an inducer of autophagy in melanoma cells. These activities are associated with inhibition of the PI3K/AKT/mTOR/P70S6K pathway. Consequently, curcumin may possess an effective antitumoral potency and provides a promising treatment paradigm for melanoma.

\section{Acknowledgements}

We would like to thank Quentin Liu for guidance in our research. The present study was supported by grants from the National Natural Science foundation of China (81472865, 81171491 and 30670650), and the Natural Science foundation of Liaoning Province (201102056 and 2014023005).

\section{References}

1. Russo A, Ficili B, Candido S, Pezzino FM, Guarneri C, Biondi A, Travali S, McCubrey JA, Spandidos DA and Libra M: Emerging targeted therapies for melanoma treatment (Review). Int $\mathbf{J}$ Oncol 45: 516-524, 2014.

2. Voskoboynik M and Arkenau HT: Combination therapies for the treatment of advanced melanoma: A review of current evidence. Biochem Res Int 2014: 307059, 2014.

3. Anand P, Sundaram C, Jhurani S, Kunnumakkara AB and Aggarwal BB: Curcumin and cancer: An 'old-age' disease with an 'age-old' solution. Cancer Lett 267: 133-164, 2008.

4. Chatterjee SJ and Pandey S: Chemo-resistant melanoma sensitized by tamoxifen to low dose curcumin treatment through induction of apoptosis and autophagy. Cancer Biol Ther 11: 216-228, 2011.

5. Siwak DR, Shishodia S, Aggarwal BB and Kurzrock R: Curcumin-induced antiproliferative and proapoptotic effects in melanoma cells are associated with suppression of IkappaB kinase and nuclear factor kappaB activity and are independent of the B-Raf/mitogen-activated/extracellular signal-regulated protein kinase pathway and the Akt pathway. Cancer 104: 879-890, 2005
6. Zheng M, Ekmekcioglu S, Walch ET, Tang CH and Grimm EA: Inhibition of nuclear factor-kappaB and nitric oxide by curcumin induces G2/M cell cycle arrest and apoptosis in human melanoma cells. Melanoma Res 14: 165-171, 2004.

7. Odot J, Albert P, Carlier A, Tarpin M, Devy J and Madoulet C: In vitro and in vivo anti-tumoral effect of curcumin against melanoma cells. Int J Cancer 111: 381-387, 2004.

8. Marín YE, Wall BA, Wang S, Namkoong J, Martino JJ, Suh J, Lee HJ, Rabson AB, Yang CS, Chen S, et al: Curcumin downregulates the constitutive activity of NF-kappaB and induces apoptosis in novel mouse melanoma cells. Melanoma Res 17: 274-283, 2007.

9. Oelkrug C, Lange CM, Wenzel E, Fricke S, Hartke M, Simasi J and Schubert A: Analysis of the tumoricidal and anti-cachectic potential of curcumin. Anticancer Res 34: 4781-4788, 2014.

10. Anand P, Kunnumakkara AB, Newman RA and Aggarwal BB: Bioavailability of curcumin: Problems and promises. Mol Pharm 4: 807-818, 2007.

11. Liu H, He Z and Simon HU: Targeting autophagy as a potential therapeutic approach for melanoma therapy. Semin Cancer Biol 23: 352-360, 2013.

12. Hönscheid P, Datta K and Muders MH: Autophagy: Detection, regulation and its role in cancer and therapy response. Int $\mathbf{J}$ Radiat Biol 90: 628-635, 2014.

13. Chu YL, Raghu R, Lu KH, Liu CT, Lin SH, Lai YS, Cheng WC, Lin SH and Sheen LY: Autophagy therapeutic potential of garlic in human cancer therapy. J Tradit Complement Med 3: 159-162, 2013.

14. Thorburn A, Thamm DH and Gustafson DL: Autophagy and cancer therapy. Mol Pharmacol 85: 830-838, 2014.

15. Siegel R, Ma J, Zou Z and Jemal A: Cancer statistics, 2014. CA Cancer J Clin 64: 9-29, 2014.

16. Alifrangis C, Koizia L, Rozario A, Rodney S, Harrington M, Somerville C, Peplow T and Waxman J: The experiences of cancer patients. QJM 104: 1075-1081, 2011.

17. Slevin ML, Stubbs L, Plant HJ, Wilson P, Gregory WM, Armes PJ and Downer SM: Attitudes to chemotherapy: Comparing views of patients with cancer with those of doctors, nurses, and general public. BMJ 300: 1458-1460, 1990.

18. Thornton M, Parry M, Gill P, Mead D and Macbeth F: Hard choices: A qualitative study of influences on the treatment decisions made by advanced lung cancer patients. Int J Palliat Nurs 17: 68-74, 2011.

19. Chinembiri TN, du Plessis LH, Gerber M, Hamman JH and $\mathrm{du}$ Plessis J: Review of natural compounds for potential skin cancer treatment. Molecules 19: 11679-11721, 2014.

20. Stewart ZA, Westfall MD and Pietenpol JA: Cell-cycle dysregulation and anticancer therapy. Trends Pharmacol Sci 24: 139-145, 2003.

21. Cho J H, Lee J G, Yang Y I, Kim JH, Ahn JH, Baek NI, Lee KT and Choi JH: Eupatilin, a dietary flavonoid, induces G2/M cell cycle arrest in human endometrial cancer cells. Food Chem Toxicol 49: 1737-1744, 2011.

22. Rozzo C, Fanciulli M, Fraumene C, Corrias A, Cubeddu T, Sassu I, Cossu S, Nieddu V, Galleri G, Azara E, et al: Molecular changes induced by the curcumin analogue D6 in human melanoma cells. Mol Cancer 12: 37, 2013.

23. Zhang L, Wang H, Xu J, Zhu J and Ding K: Inhibition of cathepsin $\mathrm{S}$ induces autophagy and apoptosis in human glioblastoma cell lines through ROS-mediated PI3K/AKT/mTOR/ p70S6K and JNK signaling pathways. Toxicol Lett 228: 248-259, 2014.

24. Ornelas IM, Silva TM, Fragel-Madeira L and Ventura AL: Inhibition of PI3K/Akt pathway impairs G2/M transition of cell cycle in late developing progenitors of the avian embryo retina. PLoS One 8: e53517, 2013.

25. Hennessy BT, Smith DL, Ram PT, Lu Y and Mills GB: Exploiting the PI3K/AKT pathway for cancer drug discovery. Nat Rev Drug Discov 4: 988-1004, 2005.

26. Lin HP, Jiang SS and Chuu CP: Caffeic acid phenethyl ester causes p21 induction, Akt signaling reduction, and growth inhibition in PC-3 human prostate cancer cells. PLoS One 7: e31286, 2012.

27. Zhou HY and Wong AS: Activation of p70S6K induces expression of matrix metalloproteinase 9 associated with hepatocyte growth factor-mediated invasion in human ovarian cancer cells. Endocrinology 147: 2557-2566, 2006.

28. Berven LA, Willard FS and Crouch MF: Role of the $\mathrm{p} 70^{\mathrm{s} 6 \mathrm{~K}}$ pathway in regulating the actin cytoskeleton and cell migration. Exp Cell Res 296: 183-195, 2004. 
29. Corazzari M, Fimia GM, Lovat $\mathrm{P}$ and Piacentini M: Why is autophagy important for melanoma? Molecular mechanisms and therapeutic implications. Semin Cancer Biol 23: 337-343, 2013.

30. Wu S, Wang X, Chen J and Chen Y: Autophagy of cancer stem cells is involved with chemoresistance of colon cancer cells. Biochem Biophys Res Commun 434: 898-903, 2013.

31. Han Z, Jing Y, Xia Y, Zhang S, Hou J, Meng Y, Yu F, Liu X, Wu M,Zhang P, et al: Mesenchymal stem cells contribute to the chemoresistance of hepatocellular carcinoma cells in inflammatory environment by inducing autophagy. Cell Biosci 4: 22, 2014.
32. Ge J, Chen Z, Huang J, Chen J, Yuan W, Deng Z and Chen Z: Upregulation of autophagy-related gene-5 (ATG-5) is associated with chemoresistance in human gastric cancer. PLoS One 9: e110293, 2014.

33. Armstrong J L, Corazzari M, Martin S, Pagliarini V, Falasca L, Hill DS, Ellis N, Al Sabah S, Redfern CP, Fimia GM, et al Oncogenic B-RAF signaling in melanoma impairs the therapeutic advantage of autophagy inhibition. Clin Cancer Res 17: 2216-2226, 2011.

34. Janku F, McConkey DJ, Hong DS and Kurzrock R: Autophagy as a target for anticancer therapy. Nat Rev Clin Oncol 8: 528-539, 2011. 